\title{
Dentrolfuera y posiciones de frontera. Transgrediendo limites entre análisis y acción desde una investigación activista con la plataforma de afectados por la hipoteca de Barcelona ${ }^{1}$
}

\author{
Inside / outside and border positions. Transgressing limits \\ between analysis and action since an activist investigation with \\ the platform of affected by mortgage of Barcelona
}

Rocío García Soto

Instituto de Migraciones (Universidad de Granada)

rogarso@ugr.es (ESPAÑA)

Recibido: 27.072018

Aceptado: 30.07 .2020

\section{RESUMEN}

En el siguiente artículo reflexionaré desde mi posición de antropóloga comprometida política y socialmente acerca de cómo he ido articulando la investigación y el activismo. Partiendo desde los cuestionamientos del para qué de la producción de conocimiento y más concretamente el para quién hacemos etnografía, me embarco en un proyecto de investigación que nacía con el doble objetivo de por un lado democratizar la producción de conocimiento y por otro politizar sus contenidos. Utilizo mi experiencia en la Plataforma de Afectados por la Hipoteca de Barcelona para visibilizar, mediante un análisis retrospectivo, los desencuentros y las dificultades con las que me he ido encontrado al compaginar la investigación con la participación e implicación en el colectivo.

${ }^{1}$ El presente artículo forma parte de la Tesis Doctoral de Rocío García Soto, autora del mismo. Se inscribe dentro de la beca FPU15/01034 del Programa Estatal de Promoción del Talento y su Empleabilidad del Ministerio de Educación Cultura y Deporte. 


\title{
PALABRAS CLAVE
}

Colaboración, implicación, movimientos sociales, universidad, compromiso.

\begin{abstract}
In the following paper, from my position as a politically and socially committed anthropologist I will reflect on the different ways I have been articulating my research and activism. Starting from the questions about the purpose of knowledge production and more specifically who we do ethnography for, I have involved myself in a research project that was born with a dual goal. On the one hand, democratizing the production of knowledge and, on the other hand, politicizing its contents. I have used my experience in the Platform of Affected by the Mortgage of Barcelona to visualize, through a retrospective analysis, the disagreements and the difficulties I have gone through while combining research with my participation and involvement within the collective.
\end{abstract}

\section{KEY WORDS}

Collaboration; involvement; social movements; university; commitment.

\section{INTRODUCCIÓN}

Escribo $^{2}$ estas páginas al estar inmersa en el proyecto de investigación colaborativa I+D+i que da vida a este artículo. Dicho proyecto: "Procesos emergentes y agencias del común. Praxis para la investigación social colaborativa y nuevas formas de subjetivación política"’3, toma en consideración varios planos de análisis. Por un lado, centrar la mirada en los procesos emergentes que se están produciendo en diferentes lugares del mundo, como resistencia a la incapacidad de un sector público y un marco institucional de dar respuestas a las necesidades de la ciudadanía ${ }^{4}$. Por otro, repensar nuestras prácticas de investigación y traspasar las dialécticas dicotomizadas propias de etnografías clásicas (entre las

${ }^{2}$ A pesar de escribir este texto en primera persona, muchas de las reflexiones que enuncio son fruto del quehacer colaborativo de la investigación. Es decir, devienen de seminarios, debates en comunicaciones en congresos, encuentros informales, asambleas, entre otros.

${ }^{3}$ Del Programa Estatal de Fomento de la Investigación Científica y Técnica de Excelencia, Subprograma Estatal de Generación del Conocimiento. Ministerio de Economía y Competitividad; Secretaría de Estado de Investigación, Desarrollo e Innovación; Gobierno de España. [Referencia: CSO2014-56960-P] cuya investigadora principal es la profesora Aurora Álvarez Veinguer

${ }^{4}$ Entre finales de los noventa y comienza del Nuevo milenio, se produce el auge de diversos movimientos (altermundista, okupa, contra la Guerra de Irak,...) que pondrán el énfasis en la precariedad como la condición paradigmática, no solo de trabajo, sino también de vida, en la época de la globalización capitalista (Mir García et al., 2013). 
cuales destaco la de sujeto/objeto). Apostando así por metodologías colaborativas (Arribas, 2014; Dietz y Álvarez, 2014) que permitan construir otras formas de producir conocimiento para continuar buscando las conexiones entre los espacios académicos y los no académicos, y promoviendo así una diversificación epistémica (Santos, 2010).

Mi aportación como parte del mismo y en este artículo, se centra en profundizar y analizar las contradicciones y los detalles metodológicos que he experimentado en la investigación, con el objetivo de intentar desplazarme del conocimiento abstracto, impersonal y descontextualizado, poniendo en valor el conocimiento del cuerpo, en tanto que sujeto de acción que experimenta, siente y se emociona ${ }^{5}$. Para ello utilizaré una narración que traspasa las fronteras del positivismo, reivindicando como sostienen Okely (2005) la imposibilidad de separar lo emocional y personal de lo conceptual en nuestra práctica etnográfica ${ }^{6}$. A pesar de encarnar esta situacionalidad, con este texto quiero ir más allá de la "reflexividad autoreferencial" (Álvarez y Dietz, 2014: 21) y compartir reflexiones que puedan llevar a cabo prácticas de diálogo con otras experiencias de coinvestigación (Leyva y Speed, 2018) .

Para dar cuenta de todo esto, comenzaré contextualizado al colectivo junto al cual comienzo a desarrollar la investigación, la Plataforma de Afectados por la Hipoteca (PAH), sin entrar en muchos detalles de la especificidad de la asamblea de Barcelona -en la que me sitúo-, la cual se irá construyendo a través del relato etnográfico que dará forma a la segunda parte del artículo. En ella narraré la experiencia concreta y organizada a través de índices temáticos que han supuesto encrucijadas, complejidades o reflexiones epistémicas para mí; que caminan desde las dificultades que tuve por encontrar reconocimiento, por legitimar mi presencia y por descubrir la utilidad como investigadora en el colectivo; hasta reconocerme a como sujeto productor de conocimiento, capaz de construir procesos colectivos más allá de las idea de partida -un tanto esencialista y colonial- de la investigación ${ }^{7}$.

${ }^{5}$ Opto por hablar de las contradicciones, no solo para hacer el conocimiento más corpóreo, sino porque como dice Hale (2018) "las contradicciones en sí mismas pueden ser aleccionadoras y construirse en fuentes de entendimiento sobre el entorno del estudio, lo que no sucedería con métodos de investigación convencionales" (307)

${ }^{6}$ Esta forma de escritura personal, emocional y a momentos ensayística ha sido por tanto una elección consciente a lo largo de todo el artículo. Y con ello asumo que la validez científica del mismo no debe situarse en la narración utilizada.

${ }^{7}$ Con esencialista y colonial me estoy refiriendo a esa forma de hacer investigación, en la cual he sido socializada en mi formación académica, que se fundamenta en prácticas de producción del conocimiento extractivas (Leyva y Spedd, 2018) Es decir, llegar a un contexto, extraer información de los sujetos del lugar y marcharse sin devolver nada o casi nada del conocimiento producido. 


\section{LA PLATAFORMA DE AFECTADOS POR LA HIPOTECA DE BARCELONA $^{8}$}

La irrupción de la crisis internacional en la economía española, iniciada en el año 2007 tuvo un impacto devastador. Las consecuencias más evidentes fueron el aumento de la pobreza y el desempleo, la insolvencia de miles de ciudadanas $\mathrm{y}$ el incremento inmediato de los desahucios. Se calcula que entre el periodo de 2008 al 2019, se han llevado a cabo mas de 1.000 .000 de desahucios. Mientras los primeros años de la crisis los desahucios eran producidos por ejecuciones hipotecarias, los datos del año 2019 rebelan que los desahucios por alquiler corresponden un $68 \%$ del total ${ }^{9}$. Estas consecuencias se debieron en gran medida a que toda la economía española de las últimas cinco décadas se había construido a partir de la especulación inmobiliaria ${ }^{10}$.

En el contexto concreto de la ciudad de Barcelona, desde la década de los 90 se producía un clima de contestación que señalaba como las políticas públicas estaban empujando la venta de la ciudad al capital, con la consecuente destrucción de formas de vida populares que suponían un estorbo en la obtención de beneficios (Delgado, 2008). Desde la era postindustrial, Barcelona evidencia un cambio en el que "los centros urbanos pasan de ser lugares de residencia a espacios de acumulación de capital" (Cócola, 2016: 33). Este cambio en la circulación de capital - de la producción industrial al mercado de la construcciónprovoca como señala Harvey (2005) que el declive de beneficios que genera la industria sea reemplazado por el aumento de la especulación inmobiliaria.

En este contexto, y tras experiencias previas ${ }^{11}$ que van a servir de impulso, nace en 2009 la Plataforma de Afectados por la Hipoteca en la ciudad de

${ }^{8}$ A pesar de existir múltiples investigaciones que abordan al colectivo de la Plataforma de Afectados por la Hipoteca (véase Suárez, 2014; Colau y Alemany, 2013; Flesher Fominaya, 2015; Mangot Sala, 2013a, 2013b) , mi intención en este apartado es simplemente situar al/la lector/a de forma superficial. Ya que la propuesta epistemológica de la investigación que aquí relato es una etnografía "junto y con" (Arribas, 2014) la PAH y no sobre la PAH.

${ }_{9}$ Datos obtenidos de la web de la Plataforma de Afectados por la Hipoteca (https://afectadosporlahipoteca.com/)

${ }_{10}$ Con la creación, en 1957 del Ministerio de Vivienda, se comienza a impulsar políticas orientadas a fomentar la compra y la tenencia privada. Todo ello con el fin de de convertir España, como afirmó el ministros Jose Luis Arrese, en un país de propietarios y no de proletarios. Con la aprobación de la Constitución Española, acontecimientos como: i) la privatización del sector bancario, ii) la entrada en la Unión Europea, y iii) la adhesión a la Eurozona, generaron un aflujo masivo de inversión extranjera, volviendo la economía española, dependiente del mercado global. A eso se sumaría, que durante el periodo de 1996-2007, los gobiernos desregularizaron el mercado de la vivienda, aprobando leyes que liberalizaron los alquileres, facilitaron la recalificación y edificabilidad de los terrenos al margen de los Planes Municipales e impulsaron megaproyectos urbanísticos (Naredo y Montiel Márquez, 2010; Gaja y Díaz, 2015; ). Pero no solo eso, con la entrada a la Eurozona, al estabilizarse la moneda y para mantener el volumen de beneficios, el sector inmobiliario necesitó incrementar el volumen de su negocio. Se abrieron sucursales por doquier y se flexibilizaron los criterios mínimos de solvencia para conceder préstamos hipotecarios (Suárez, 2014; Colau y Alemany, 2012).

${ }^{11}$ Cabe resaltar que la PAH no nace desde cero, sino que sus orígenes se remontan a expe- 
Barcelona, tras una reunión conjunta de personas afectadas y activistas (Colau y Alemany, 2013; Flesher Fominaya, 2015; Mangot Sala, 2013b). La primera campaña que comienza a visibilizar al colectivo a través del eslogan: "este banco engaña y estafa y echa a la gente de sus casas", apuntaba directamente a las entidades financieras como las principales responsables de la crisis (Mangot Sala, 2013a). A partir de aquí la organización creció y las asambleas se multiplicaron primero por la comunidad catalana y más adelante por el resto del Estado, alcanzando en 2019 más de 200 nodos.

Cuando la PAH es fundada, sus objetivos mínimos son tres: conseguir una ley que establezca la dación en pago retroactiva, una moratoria de los desahucios y la creación de un parque público de viviendas de alquiler social (Domingo Utset, 2012; Colau y Alemany, 2013). Para lograrlos, la plataforma se organiza mediante asambleas locales que funcionan como el órgano principal de decisión, lugares de emancipación y resistencia (Domingo Utset, 2012) donde los problemas individuales y los estigmas sociales se colectivizan en forma de denuncia y reivindicación política ${ }^{12}$.

\section{ENCRUCIJADAS ANTE LA EXPERIENCIA}

En el siguiente apartado voy a relatar mi experiencia de investigación de los últimos años describiendo y analizando todas las emociones, desplazamientos y desventuras que he atravesado para poner la memoria sobre la mesa de trabajo. Propongo hacer uso de la herramienta de la "reflexividad"13 (Ferrandiz, 2011) para analizar críticamente las decisiones metodológicas que tomé en el marco de la investigación. En este sentido, aunque se hace inverosímil reducir en tan pocas palabras los últimos años, narraré en orden cronológico lo sucedido, eligiendo $\mathrm{y}$ ordenando algunos hechos en base a las problemáticas fundamentales con las que me he topado. En tres grandes apartados caminaré desde la complejidad de acercarme como investigadora en un colectivo en lucha, a la necesidad de reco-

riencias pasadas como las del "Movimiento por la Vivienda Digna" (2003) o "V de Vivienda" (2006). Dada las limitaciones de extensión, recomendamos para más información remitirse a los trabajos de: Álvarez de Andrés et al. (2014); Colau y Alemany (2012 y 2013); Mangot Sala (2013a y 2013b); Mir García, França, Macías y Veciana (2013); Sebastiani, Fernández y García (2016) y Veciana et al. (2013)

${ }^{12}$ La campaña de Stop Desahucios fue como dice Macías (2013), el ejemplo del proceso de la colectivización del estigma: "transformar el imaginario colectivo ha desactivado el estigma del desahucio y la ocupación y han activado el de la dignidad y la solidaridad, a la par que ha permitido hacer efectiva la autotutela del derecho a la vivienda" (48). Además de practicar la desobediencia de leyes injustas, la PAH ha llevado a cabo campañas como la propuesta en 2013 de una Iniciativa Legislativa Popular, o la tramitación de la ley catalana 24/2015.

${ }^{13}$ Con reflexividad me estoy refiriendo al conjunto de acciones reflexivas que están encaminadas a cuestionarse: "por qué se elige un tema determinado, en relación con qué debates, por qué se acota el objeto de investigación, cómo se hace, por qué se toman determinadas decisiones metodológicas, y por qué se eligen determinadas retóricas para expresar el conocimiento adquirido" (Ferrandiz, 2011: 41) 
nocimiento por parte del colectivo que me despertó una voluntad de implicación. Pasaré por las tensiones identitarias y las relaciones de poder han generado la ficticia -que más adelante explicaré- doble lealtad investigadora y activista, a la obsesión por buscar un común que las aunara y diera coherencia a mi presencia como etnógrafa. Movimientos que, como se verá más adelante, acaban por concretarse en procesos múltiples de investigación, que en el marco de un colectivo social, me permitirán elaborar herramientas -junto a más compañeras- que van a poner la lucha por el derecho a la vivienda en el centro.

\subsection{Aterrizando en la investigación etnográfica}

Fruto de mi formación durante el Grado de Antropología Social y Cultural en la Universidad de Granada comencé a bailar entre el desafecto por la institución universitaria y los intereses por otras formas de producir conocimiento. Continuando con la espiral formativa universitaria me inscribí en un Máster de Antropología i Etnografía en la ciudad de Barcelona. Las posibilidades de ese año de formación vinieron marcadas entre otras razones, por el apoyo financiero familiar/institucional. El hecho de haber elegido Barcelona como ciudad de destino vino determinada por un lado por la popularidad que tienen algunos de los docentes de la Universitat de Barcelona, de los cuales me quería nutrir; y, por otro lado, por la efervescencia en términos de movimientos sociales y acción colectiva que se despliegan en la ciudad, la cual me atraía. A todo esto se sumaba que el proyecto I+D+I iba a comenzar su investigación junto a los grupos de vivienda Stop Desahucios 15M de la ciudad de Granada ${ }^{14}$, por lo que mi presencia en Barcelona propiciaba expandir la investigación a este contexto, teniendo en cuenta que la Plataforma de Afectados por la Hipoteca nace en la ciudad de Barcelona en el año 2009.

El participar en el proyecto I+D+i me permitió compartir conocimientos con personas que se encontraban en mi misma situación, con un pie dentro y otro fuera $^{15}$, entre la duda y la ilusión; lo que me hacía continuar descubriendo alicientes. Siempre en los momentos de más desilusión con lo que hacía, emergían posibilidades de las grietas, de las periferias de una disciplina "al margen y en el centro" (García, Álvarez y Rubio, 2011). Y es, quizás, como afirma Camarroff (2010), "el permanente estado de crisis de la Antropología, su in-disciplinamiento" (254), donde se encuentran las potencialidades.

${ }^{14}$ El estudio de caso de Granada, impulsado por nuestras compañeras Ariana Sánchez Cota, Luca Sebastiani, Antonia Olmos y Aurora Álvarez Veinguer, se ha estado desarrollando bajo las mismas premisas epistémicas junto al colectivo Stop Desahucios Granada 15M. Dando comienzo a la investigación al mismo tiempo que nosotras.

${ }^{15}$ Como dos de mis compañeras del proyecto $\mathrm{I}+\mathrm{D}+\mathrm{i}$ reflejan en un artículo: "consideramos que hay que habitar, e incluso fomentar, ese estado de tensión productiva, de incomodidad creativa, que puede abrir posibilidades y horizontes (Arribas, 2014), para ir superando la dialéctica del tú aquí y yo aquí (Calle, 2012: 229)" (Cota y Sebastiani, 2015: 56). 
Los primeros meses en Barcelona fueron de lo más agobiantes. Tirando de redes de afecto me mantuve en casas ajenas mientras desesperada buscaba unas paredes que alquilar. Nunca había habitado y mucho menos alquilado en lo que era una "gran ciudad", y por primera vez encarné las consecuencias más directas del modelo inmobiliario español. Los precios desorbitados nos expulsaban de la ciudad y el monopolio de las rentas por parte de las inmobiliarias provocaron -y siguen provocando- que el acceso a la vivienda fuera realmente difícil. La tremenda competitividad entre arrendatarios otorgaba todo el poder de negociación a los intermediarios, que lo utilizaban para introducir cláusulas abusivas irrevocables. Y por si fuera poco, salí de mi tremenda inocencia cuando tomé conciencia que la legislación estaba única y exclusivamente hecha para los arrendatarios ${ }^{16}$. Donde el alquiler era una opción de lo más inestable, con un máximo de tres años de renta y la obligación de un contrato de trabajo o de un avalista para la firma del alquiler -solvencia que por otra parte, estaba en competencia con otras arrendatarias interesadas en el inmueble, haciendo del alquiler, no sólo una competición racista (sin papeles, no hay trabajo, sin trabajo no hay vivienda) sino que también sexista, clasista y edadista. Era claro que mi status de estudiante en Granada no me había permitido experimentar la vivienda como privilegio y objeto de mercado.

Independientemente de los estudios de máster que había ido a realizar allí, para mi el I+D+i era lo que daba sentido a mi presencia en Barcelona. Había asumido el compromiso con el resto del equipo de llevar a cabo una investigación que generara conocimientos que fueran útiles tanto para el colectivo de la PAH como para la academia, a la que en parte se debía mi currículum.

A pesar de que anteriormente me había acercado a la etnografía colaborativa, para mi era todo un reto llevarla a cabo. Había leído textos como el de Grenwood (2008), Medela y Montaño (2011) o Hale (2001) que me hacían entender que no podía haber etnografía colaborativa sin un compromiso previo con las personas-colectivos y la causa por la que luchaban. Y añadían que si se quiere construir una pregunta de investigación compartida, una investigación junto y con, había que "desplazarse de lo ajeno al nosotros, del "sus" realidades al "nuestras" realidades" (Medela y Montaño, 2011: 24). Es decir, debía pasar de ser investigadora neutral a sujeto político.

En un principio, para mí, la legitimidad de activar esta investigación no estaba situada en la PAH y sus reivindicaciones, sino más bien en aquellas personas con las que había compartido el compromiso por otras formas de investigar, aquellas que formaban parte del $\mathrm{I}+\mathrm{D}+\mathrm{i}$. Y esto en parte se explica porque no participé de la elaboración del proyecto, en el por qué, para qué y cómo; sino que me sumé a él una vez había sido definido y puesto en marcha. Reflexiones que

16 En el año 2017 nacen en Madrid y Barcelona los sindicatos de inquilinas, con el objetivo de cambiar la Ley de Arrendamientos Urbanos, la cual consideran injusta. Jaime Palomera, portavoz del Sindicat de Llogaters de Barcelona afirma que "la legislación no pone límite, tú puedes incrementar el precio un $250 \%$ y el inquilino está en una posición estructural débil, porque la ley es muy poco garantista con el vecindario, con los barrios" (Iborra y Calvó, 2017). 
al comienzo de la investigación fueron de gran importancia para poder seguir caminando. Y así lo plasmaba en el diario:

Es cierto que mi primer interés ha surgido con la necesidad de explorar nuevas formas de investigar colaborando, es decir, es cierto que he estado primeramente comprometida con la producción de conocimiento y que es a partir de esta militancia que me acerco al compromiso con la PAH; pero eso no necesariamente supedita la PAH al proyecto. Partiendo de la base que el compromiso con formas de investigación militante, tiene como premisa comprometerse con los implicados y sus luchas y necesidades de transformación social, el primer compromiso no excluye ni supedita al segundo sino que lo abraza, han de ir de la mano. No podemos pensar una investigación colaborativa sin este doble compromiso, es más, encuentro absurdo duplicar o multiplicar el compromiso. Una vez que se comienza a andar con la gente el compromiso acompaña el proceso (Diario 16/11/15)

Siguiendo los pasos del grupo de Granada, decidí comenzar a asistir a las asambleas de la PAH de Barcelona para poner en marcha la investigación. El proceso de "entrada" fue bastante complejo. Dado que me proponía llevar a cabo una investigación al margen, que dislocara las jerarquías sujeto/objeto, era muy importante el cómo me acercaba. A pesar de que en muchos contextos de investigación etnográfica la figura de la "portera" 17 es crucial, en mi caso y dadas las características del funcionamiento de la asamblea, no me ayudó en "la entrada"18. Debía presentarme y darme a conocer como una más. Durante mi presentación en el colectivo me di cuenta de mi incapacidad para comunicar qué quería hacer en ese lugar. Había defendido el proyecto en múltiples espacios académicos (becas, máster, doctorado) en los que definía muy bien nuestros intereses, nuestros puntos de partida y los principales objetivos del mismo. Era plenamente consciente del oscurantismo ${ }^{19}$ que presenta la academia, y del desplazamiento que debía realizar para abandonar la ignorancia de ese homo academicus (Bourdieu, 2002). Toda una tarea de traducción que, partiendo del cuestionamiento del conocimiento académico como el único válido, me ayudara a construir "constelaciones compartidas de sentido para que la ampliación del

17 En los casos en los que la persona que investiga es ajena al grupo en el cual se va a desarrollar la investigación, en el acceso al lugar donde se va a realizar el trabajo de campo, suele dares una figura fundamental: el portero o portera. En palabras de Hammersley y Atkinson (1994) "son aquellos actores que controlan recursos clave y pasajes, desde donde se conceden oportunidades" (50). En definitiva, son personas que tienen el poder de facilitar o bloquear el acceso al contexto de la investigación.

18 Es interesante hacer notar las ideas de entrada y salida del campo. La cuales nos dibujan un espacio físico, con fronteras claramente marcadas, las cuales como dice Clifford (1999) "presuponen una distinción especial entre una base conocida y un lugar exterior de descubrimiento" (72).

19 Por oscurantismo en la academia me estoy refiriendo a la falta de comunicación que existe con la sociedad en general. Lo cual la hace opaca. Entre otras cuestiones por ese lenguaje único que utiliza. Caracteriza por "términos, reglas y definiciones hechas para excluir ambigüedades semánticas y contradicciones sintácticas o lógicas" (Dieterich, 1996: 96). Un lenguaje esotérico, inaccesible a la mayoría de la población, y que parece, como dice Lecourt (1977) "guardar un secreto en posesión de solo aquellos que los comprenden" (155). 
presente -conversación entre voces- no derivara en mera dispersión" (Arribas, 2014: 58). Sin embargo, todas estas buenas intenciones no terminaron de aterrizarse en mi presentación. Con las manos sudorosas cogí el micrófono e intenté explicar lo mejor que pude los propósitos que me habían llevado hasta allí:

Comenzamos hablando, mencionando quiénes éramos (investigadoras comprometidas con la PAH y con construir algo colectivo) y de dónde veníamos (de Granada donde ya ha comenzado una investigación con la gente de la asamblea Stop Desahucios Granada 15M). Intentamos dejar muy claro el por qué estábamos allí. Explicando principalmente el proyecto (el cual se centra en el cómo se investiga y no tanto en el qué se investiga) y nuestra propuesta de trabajo. En definitiva, propusimos que queríamos poner en marcha herramientas para investigar entre todas, algo que creyéramos útil, necesario o urgente en la plataforma. Pero nuestra intervención fue algo tormentosa. No esperábamos que la dinámica se sucediera así, con un "apartado" específico para presentar cada unx su propuesta de investigación. Percibí en las caras de la gente aburrimiento, pensando, bueno, una investigación más (Diario 17/11/15).

Si bien esta carta de presentación fue algo que legitimó mi presencia en las acciones y asambleas, tuve que hacer eco del por qué y para qué estaba allí en repetidas ocasiones. Eran preguntas que también me hacía a mi misma y que me ayudaban a indagar e indagarnos constantemente. Aunque la idea en un principio era que después de la presentación debía empezar a pensar colectivamente en qué herramientas podíamos articular que fuesen útiles para el colectivo y la transformación social, estaba claro que eso no iba a ser tan sencillo. Fui consciente desde un principio de la importancia de estar comprometida políticamente para generar común ${ }^{20}$. Entendí que si quería llevar a cabo una colaboración, ésta no tendría sentido plantearla en términos de investigadora-paracaídas, con propuestas cerradas y agendas pre-establecidas. Así, mi rol y deseo en aquellos primeros momentos fue de atender, escuchar y aprender para intentar buscar respuesta a ¿cómo generar un espacio para construir común?, ¿desde dónde?.

\subsection{Aprendiendo a "militar"}

Los comienzos no siempre son fáciles, y mi proceso de reconocimiento y aceptación por parte del grupo se prolongó más meses de lo que me hubiera gustado. Por un lado debido a las características del propio movimiento. La asamblea de la PAH de Barcelona es la primera que dio vida al colectivo. Una asamblea que reunía -y sigue reuniendo- cada lunes y martes alrededor de 150200 personas, donde pasar desapercibido era de lo más habitual. Y más aún

${ }^{20}$ Entiendo lo(s) común(es) "como recursos materiales para sostener la vida y como proceso de movilización [...]. Como una forma de organización que pone en práctica principios comuneros, principios como la profundización democrática, la auto tutela de derechos, o la autogestión." (Observatorio Metropolitano de Barcelona, 2014: 4). 
cuando tu presencia venía determinada por una investigación; donde por tanto tu identidad no estaba asociada a un banco o a una trayectoria habitacional, sino que por el contrario, al no exponerte públicamente en las asambleas, era habitual ser identificado como parte del "público".

Por otro lado, mi incapacidad para integrarme dentro del grupo también vino determinada por la dificultad de encontrar afinidades políticas con las "afectadas" 21 . Un espacio con gran diversidad de historias y contextos que confluían en tres siglas (PAH) que si bien o no me decían nada o me producían emociones contradictorias. Por un lado, estaba la ausencia de referentes en los lenguajes. Modelos y marcos ideológicos que en un pasado me habían hecho movilizarme políticamente, aquí se ahogaban en una gran cantidad de tecnicismos y humanismos que no me convencían. Y me preguntaba ¿dónde estaba toda la terminología anticapitalista, anarquista, antipatriarcal o decolonial?. En esos primeros instantes tuve la sensación de que nos limitábamos, como movimiento, a resolver casos particulares con la máxima aspiración de cambiar la legislación. Sentía a la PAH casi como un órgano de gobierno que daba respuesta allí donde la Administración no llegaba, recogiendo a toda la masa crítica de personas sin casa y acomodando esa violencia institucional en demandas reformistas (y no revolucionarias ${ }^{22}$. Pero pocas semanas después comencé a darme cuenta que todo lo que se movía durante las asambleas iba más allá de los típicos mítines políticos a los que estaba acostumbrada. Todas aquellas personas, sin ser afiliadas a ninguna ideología común, se empoderaban, se organizaban, se cuidaban y no suficiente con eso, se enfrentaban a bancos, ocupaban edificios, plantaban cara a la administración, a los partidos políticos y sacaban adelante una Iniciativa Legislativa Popular ${ }^{23}$. Y escribía en el diario: "cada día que voy a la PAH descubro una nueva capacidad, logro o habilidad que me sorprende y que ya vaticina la siguiente. Sus capacidades son ilimitadas" (Diario, 17/11/15). Este enamoramiento hacia el colectivo venía determinado en gran medida por ser mi primera experiencia militante. A pesar de haber participado en las asambleas del $15 \mathrm{M}$ y en diversas manifestaciones a favor de derechos sociales en la ciudad de Granada, nunca había asumido la responsabilidad de comenzar a participar con ningún colectivo.

${ }^{21}$ El concepto de afectadas es utilizado por la PAH como estrategia política para enmarcar lo que en sus inicios parecía un problema personal en un problema estructural. Y así lo explican en uno de sus documentos: "todos y todas somos afectados por la hipoteca: las políticas de vivienda de la burbuja inmobiliaria, la estafa hipotecaria y la mala praxis bancaria están en el origen de la crisis que hoy condena a millones de personas al desempleo y la precariedad" (PAH, 2010: 6)

${ }^{22}$ Véase el concepto de reformismo aplicado al uso que hace la PAH de la ocupación: "la PAH utiliza la expropiación para negociar con los bancos propietarios de los inmuebles temporalmente expropiados. Para esta plataforma ciudadana la expropiación es una herramienta de coacción, de presión, de fuerza para provocar que las entidades bancarias negocien unas determinadas condiciones. Es ocupación (...) La PAH evita intencionadamente cualquier vinculación con el significado de la palabra okupar. Se trata de una corriente de corte ciudadanista que no pretende una ruptura radical con el sistema de dominación" (Okupa, resiste, crea, 2014: 16)

${ }_{23}$ Para más información ver: http://afectadosporlahipoteca.com/category/propuestas-pah/ iniciativa-legislativa-popular/page/2/ 
Durante estos meses en busca de un lugar en la plataforma, me dediqué a comprender el funcionamiento de la PAH a través de las acciones, asambleas y talleres, además de todo el procedimiento a seguir para defendernos de la estafa inmobiliaria ${ }^{24}$. Me di cuenta que todo este primer ritual de "acceso" se tradujo en una obsesión por desligarse del rol de investigadora al uso. Necesitaba sentirme parte del grupo junto con el que quería investigar. Una búsqueda de reconocimiento constante que terminó por borrar mi capacidad de análisis. Y así lo plasmaba en el diario :

Hasta ahora he conseguido no pasar del todo desapercibida, "ser aceptada" por así decirlo dentro del paisaje de la asamblea y las acciones. Mi cara ya no es del todo extraña. Pero en tanto que no saben mi nombre, siguen sin entender qué hago allí y para qué, quedo relegada a una práctica de observación participante. Las dimensiones del grupo hacen que se requiera invertir más tiempo para agilizar el proceso (tengo prisa?). Creo que demuestro interés, pero todavía no es suficiente, pues siempre percibo las sospechas de que es un interés supeditado a la investigación y no a la PAH. Aquí la cuestión parece ser, invertir más tiempo desde las comisiones y conseguir una implicación que me integre dentro de la familia. Cada vez parece más claro (aunque me cuesta escribirlo) que si no soy PAH, no puede haber un compromiso desde el colectivo y por tanto, no puede llevarse a cabo una colaboración sana. (19/01/16)

Aunque en un principio estaba pasando por lo que toda antropóloga ha de pasar cuando realiza trabajo de campo y observación participante, mi interés era indagar en cómo ir más allá de éste posicionamiento clásico y jerárquico de la investigación. Cómo posibilitar otra fórmula relacional a pesar de no conocer al grupo antes de plantear el deseo de investigar.

Por aquel entonces ya había aprendido que la observación participante era una herramienta fundamentalmente identitaria de la Antropología. Ésta se consolida en el contexto de la Antropología Funcional-Estructural a partir de las aportaciones de Durkheim. El cual hablaba de que los hechos sociales son separables de los individuos; sirviendo esto como el soporte teórico de la Antropología Social Británica (Guber, 2001). A partir de aquí la observación participante se ha configurado como un aparato metodológico que da cuenta de la autoridad etnográfica (Clifford, 1995: 40). Una autoridad que busca legitimidad para definir aquello que ocurre en "el campo" a través de una práctica empirista:

...ha nacido del discurso estrictamente positivista y objetivador que buscaba el reconocimiento de la práctica empirista dentro de las ciencias sociales apoyándose en el propósito de la "pura" captación del contexto observado, a un devenir incierto atravesado por la subjetivación de la observación que mira y que practica la observación (Ellen, 1990: 20, citado en Álvarez Veinguer, 2012: 6)

${ }^{24}$ En la PAH se habla de estafa inmobiliaria y no de crisis para visibilizar que la injusta y dramática situación por la que han pasado tantas personas es consecuencia directa de: políticas públicas encaminadas a convertir la vivienda en un negocio y entidades financieras que han conseguido beneficios multimillonarios mediante la concesión de préstamos hipotecarios abusivos. 
En este sentido, me identificaba más con Greenwood (2000) cuando nos explica que la técnica de la observación participante se ha popularizado invisibilizando la responsabilidad que tiene el supuesto "espectador"; la cual genera una especie de ficción profesional que reclama autenticidad de la presencia en una situación determinada de cuya influencia intenta escapar. Una técnica que pone el foco en el rol de la observación y adjetiva la participación. Desde aquí, el mismo Greenwood nos propone la noción de participación-observante como una forma de poner el foco en lo relacional y en el compromiso y la confianza que de aquí se despierta.

A pesar de que pretendía de esta forma instrumentalizar la investigación y no la participación pensando que éste compromiso metodológico posibilitaría otros más relacionales, realmente no sabía para qué ni con quién instrumentalizar la investigación. Me sentía atrapada en la figura de investigador "outsider" y no conseguía implicarme, sentir de ésta mi gente y de sus gritos mis luchas. No era fácil, no terminaba de integrarme, no entendía aún bien el funcionamiento y la gestión de las asambleas ni del colectivo en general, ni si quiera comprendía bien la terminología. Cuando el grupo no me identificaba, ni me sentía identificada con él, me daba cuenta que la causa por la que creía estar comprometida no parecía ser la misma por la que me pasaba horas debatiendo en asambleas. En estos momentos se evidenció mi incapacidad para escuchar y analizar la situación. No supe asumir el desafío de aprender a preguntar y a callar y me puse a actuar. Una confrontación pensamiento/acción que venía determinada en parte por la presión constante que sufría al estar cursando un máster; en el cual clase tras clase me demandaban resultados de la investigación. Una confrontación con el método lento, vulnerable, diverso e incierto que quería poner en marcha junto a la $\mathrm{PAH}$ de Barcelona.

Los trabajos y las clases de este máster sabían cada vez más superficiales (a pesar de entusiasmarnos a nuestra llegada al mismo), y por si fuera poco, se nos exigía constantemente prudencia, distanciamiento y neutralidad en nuestras investigaciones. Lo que provocó que empezara a sentir a la universidad -de forma esencialista- como un agente hostil ante el cual mi mejor defensa eran las caretas de la PAH. Cuanto más distancia me exigían, más posicionada me sentía. Las siglas P-A-H se convertían en trinchera frente a la "autoridad académica" que pretendía definir y calificar cómo debía investigar. En esos momentos no fui consciente del pulso identitario PAH/Academia al que estaba sometiendo la situación. A pesar de que era una separación que rechazaba, caí en ella sin ser suficientemente reflexiva. Todo un posicionamiento binario que dibujaba a la academia como un espacio que no sirve y a la PAH como un espacio de transformación. Los requerimientos urgentes de un movimiento que enfrenta desahucios, cortes de suministros, acompañamientos y acciones de manera continuada los confrontaba con el mundo de la academia. Lo que me generó todo un proceso de enamoramiento hacia el colectivo, resultando así bastante difícil anteponer la reflexión y la escritura a la lucha en la calle.

Sin embargo, no todo lo entendía en términos PAH/universidad, sino que también encontraba refugio en esa periferia disidente que en ese momento cons- 
tituían nuestras compañeras del proyecto de investigación I+D+i. La búsqueda del diálogo de saberes (Sousa Santos, 2010), de superar la relación sujeto investigador/objeto investigado(Gregorio, 2014; Arribas, 2014) y de profundizar en procesos, no productos (Álvarez y Dietz, 2014), era algo que teníamos por la mano. Por no hablar de la crítica a la neutralidad y a la voluntad de partir de la situación para impulsar la transformación que nos enseñaron experiencias como la investigación militante de Marta Malo o el COLECTIVO SITUACIONES (VV. AA., 2004: 35), la pedagogía del oprimido de Freire (1969), la Investigación Acción Participativa (Villasante, 2010: 15) o la coinvestigación obrera (VV. AA, 2004: 16) entre otras.

\subsection{Pulso identitario entre militancia e investigación}

A partir de aquí comprendí que si quería ser útil y abrir un espacio de colaboración, debía aprender las prácticas PAH aún a riesgo de ser PAH. Durante ese proceso me di cuenta que cuanto más aprendía en las asambleas más útil me sentía, cuanto más útil me sentía más responsabilidades desempeñaba, más me reconocían y más cobraba sentido y fuerza mi presencia. El hecho de asumir tareas y roles, hizo dejarme llevar por esa buena sensación de ser saludada, llamada y encomiada. Ir aprendiendo a militar y ser reconocida como tal, era una sensación de lo más reconfortante.

En ese momento, el colectivo atravesaba un conflicto que provocó (además de conflictos personales) la división de la asamblea en dos posiciones enfrentadas $^{25}$. Para mí, este conflicto sirvió de chispa para desencallar el colapso en términos de investigación que estaba viviendo. ¿Qué estaba haciendo allí además de luchar junto al colectivo por el derecho a una vivienda digna? Mientras mis compañeras se ahogaban en el conflicto, mi decisión fue distanciarme y ver a éste como una gran oportunidad, una forma de profundizar y transformar el funcionamiento de la asamblea de Barcelona. Fundamentalmente, para mí esto suponía una salida de meses estando perdida. Haber estado buscando, esperando e ignorando el camino hacia la colaboración hasta llegar al colapso, me hizo percibir esto como una gran oportunidad de intervención. En esta situación de conflicto, en la que ya gozaba de un reconocimiento habiendo sido una "compah" 26 más, la cualidad de ser investigadora volvía a cobrar sentido. Ahora que estaba legitimada en el interior del colectivo, que sabía cómo funcionaba y

${ }^{25}$ Se trató de un conflicto político que estaba polarizado en dos grupos claramente definidos de la asamblea de Barcelona. El conflicto tenía que ver: i) con las formas de funcionamiento interno de la asamblea y la gestión de la información; ii) con la relación que existía entre la asamblea de Barcelona y el resto del colectivo y asambleas del Estado; y la más importante iii) con la visión acerca de la ocupación como práctica política para realojar a las familias desahuciadas por los bancos.

${ }^{26}$ Compah es una expresión que se utiliza dentro de la PAH para referirse a las activistas del movimiento, para hablarse entre compañeras de lucha. Provienen de la unión de las palabras compañera y PAH. 
me había sentido identificada como para defender un posicionamiento "junto y con" (Arribas, 2014), , el rol de investigadora podía ser instrumentalizado para generar un distanciamiento frente al conflicto. La propuesta partía de la escasez de tiempo que vivíamos en las asambleas para atender las dinámicas internas del movimiento. Y se concretaba en crear un grupo de trabajo, un grupo motor que activase y dinamizase qué nos ocurría como colectivo y hacia dónde queríamos ir. Para ello era necesario la creación de pequeños grupos de escucha, que sirvieran como pretexto para parar el tiempo y expresar de forma tranquila y participativa qué elementos habría que modificar en el movimientos y cuáles estaban funcionando bien.

Pero con una mirada reflexiva, ahora me doy cuenta de que no fui consciente de cómo estaba construyendo a las personas que forman parte del colectivo para justificar y desarrollar mi idea de investigación. Desde este planteamiento creía que mi utilidad como investigadora pasaba por "enseñar" a las activistas sobre qué tenían que hacer, asumiendo que en esa situación de conflicto había alguien que sabía y que esa era yo. Encarné todo un rol de "mesías" que la asamblea no permitió que saliera adelante. Al no encontrar lugar como investigadora-en los términos en los que lo planteaba- la situación de conflicto que atravesaba el movimiento me hizo posicionarme. De nuevo leí la realidad en términos polarizados, un prisma que se asemejaba a mi forma de entender la investigación y la militancia, a "estás con una o estás con otra".

Con el tiempo, la presión por encontrar o construir un espacio común la iba relegando. Mi incapacidad para posicionarme en las fronteras -del conflicto, de la investigación y de la militancia- hizo que tomara parte en el conflicto y defendiera con uñas y dientes a mis compañeras de Obra Social ${ }^{27}$, provocando mi expulsión del colectivo junto a 25 personas más ${ }^{28}$.

Por aquel entonces comprendí que mi forma de vivir la investigación que tantos quebraderos de cabeza me había causado por hacerla posible era preci-

${ }^{27}$ La Obra Social es una comisión de trabajo dentro del colectivo que surge como campaña en diciembre de 2011 (su título parodiaba las obras sociales de las cajas de ahorro, marcadamente la de La Caixa-Catalunya). Consistía en la reapropiación de viviendas vacías propiedad de los bancos y fruto de desahucios (Macías, 2013: 48), para realojar a las personas que se habían quedado sin casa (Mangot Sala, 2013a). El objetivo solía ser el de forzar al banco a legalizar la situación existente y obtener el alquiler social (Colau y Alemany, 2013: 62). Como queda reflejado en el Manual de la Obra Social, “(...) es una campaña de ocupaciones y recuperaciones del derecho a la vivienda que responde a un estado generalizado de emergencia habitacional generado de forma artificial y deliberada por los bancos y el gobierno" (Obra Social la PAH 2013: 4). Con ésta práctica, actualmente la OS ha ocupado 49 bloques, con cientos de recuperaciones individuales y más de 3000 personas realojadas.

${ }^{28}$ Como he dicho anteriormente, el conflicto estaba divido en dos posiciones y uno de ellas la encarnaba una de las comisiones de trabajo de la asamblea: la obra social. Yo, desde mi entrada en el colectivo venía trabajando con ellas. Y de hecho, en la asamblea se me identificaba como parte de esa comisión. Es por ello que cuando el conflicto alcanzó su punto más alto y totalmente polarizado, fue difícil desmarcarse de él. Pero no sólo eso, sino que compartía -con mis compañeras de Obra Social- afectos y convicciones políticas que me hicieron posicionarme, y que terminaron con nuestra expulsión de la asamblea. Mi investigación no tenía sentido pensarla sin ellas, por lo tanto, debía estar con ellas. 
samente lo que la hacía imposible. Una búsqueda que se anulaba a sí misma y que quebraba la tesis inicial que impulsó la investigación. Porque, ¿qué era para mi en definitiva investigar? Y más aún, ¿qué era investigar junto y con los movimientos sociales? Durante todos esos meses me di cuenta que a pesar de sentirlas compañeras de lucha, seguía sin entenderlas como sujetos productores de conocimiento, donde la única que podía llevar a cabo una investigación era yo.

Desde aquí, y tras muchas horas de análisis, entendí que reconocer a los "otros" como sujetos productores de conocimiento pasaba por dejar de plantear la investigación como algo inherente a la universidad, tomando conciencia de los procesos de producción de conocimiento cotidianos. Donde colaborar no era algo que debía ser necesariamente pactado entre entidades o identidades diferenciadas, sino que también lo era cuando esos procesos cotidianos se conformaban en colectivo y se les daba sentido. Y eso fue lo que guió el proceso grupal atravesado por la Obra Social Barcelona $(\mathrm{OSB})^{29}$

\section{4. ¿Comienza la colabor-acción?}

Fue a partir de aquí donde empezó la colaboración junto y con el colectivo la OSB. El hecho de haber tenido que reconfigurar nuestra militancia en la lucha por el derecho a la vivienda, me permitió re-situarme como parte activa del mismo. Ya no era una persona que había venido al colectivo para realizar una investigación, sino que era parte del colectivo, aún queriendo realizar esa investigación. Todo un proceso de transformación en el que pasé de estudiar como dicen Medela y Montaño: "un movimiento ajeno a nuestras vidas a convertirnos en sujetos mismos de nuestro análisis, asumiendo "sus" realidades como "nuestras" realidades" (2011: 42). Y esta forma de entender lo que pasaba a nuestro alrededor vino directamente marcada por el paso de ser/identificarme como investigadora -en los términos en los que lo plateaba al comienzo- a sujeto político. Todo un cambio de posicionalidad que fluctuaba entre: generar y alimentar debates relevantes para el movimiento por un lado, y hacer propaganda del movimiento entre los espacios más académicos por otro. Pero veamos el proceso de forma detallada.

El colectivo de la OSB había nacido con el objetivo de reivindicar la ocupación $^{30}$ como práctica de lucha a favor del derecho a la vivienda. Para ello, hasta

${ }^{29}$ A partir de ser expulsadas de la asamblea de la PAH de Barcelona, decidimos seguir luchando por el derecho a al vivienda constituyendo un nuevo colectivo llamado Obra Social Barcelona.

${ }^{30}$ Un apreciación con respecto al concepto de ocupación, utilizando las palabras del colectivo Obra Social Barcelona: "En muchos ambientes se genera la distinción entre recuperación, ocupación, y okupación. A grandes rasgos, esta división asocia las dos primeras a la necesidad habitacional y la tercera a una ideología política que denuncia la propiedad privada y sugiere, en muchos casos, alternativas de autogestión. A los ojos de la sociedad, esta diferencia acaba traduciéndose respectivamente en la concepción de dos perfiles ocupas: los buenos y los malos. Sin embargo, desde nuestro punto de vista, cualquier tipo de ocupación ya sea por cuestiones de necesidad in- 
la fecha, ha ocupado de forma colectiva tres bloques en la ciudad de Barcelona ${ }^{31}$, además de impulsar una campaña que permita desestigmatizar la práctica de la ocupación en Cataluña. Dentro de este contexto, y ligándolo con lo que decía más arriba, estos procesos de (re)construcción del colectivo se construyeron a través de investigaciones, aunque estas no sean reconocidas por los regímenes expertos. Entre las cuales podríamos distinguir tres líneas: indagación-recuperación grupal; campaña de legitimación de la ocupación; y acompañamiento a los bloque ocupados. Es claro que la simplificación en tres procesos es sólo una estrategia explicativa para poder profundizar en lo invisible y reflexionar acerca de cómo la investgación (instrumento de nuestros objetivos) se desarrolló. A continuación las presento por orden de consecución.

\subsubsection{Investigación indagación}

Esta primera línea investigativa todavía respiraba los últimos coletazos del descuadre de la expulsión. El grupo atravesaba un proceso postraumático (la PAH había supuesto las 24 horas del día para la mayoría de nosotras) por el cual, muchas de las personas requeríamos tiempo para asimilar el divorcio. Dentro de este movimiento intestinal, en el que continuamos juntándonos para cuidarnos tras lo sucedido, sentí de nuevo que podía llegar a tener un rol privilegiado. Al principio, volví a intentar resituarme sustituyendo a la PAH por la OSB como el colectivo con el que pretendía colaborar. Y desde ahí, caminé algunos pasos atrás (en lo que a lo aprendido metodológicamente se refiere) intentando dinamizar algunas reuniones que nos ayudasen a definir que (no) queríamos ser y hacia dónde queríamos ir como nuevo colectivo. Pensé que como investigadora, estimular un proceso auto-reflexivo dentro de un colectivo, era ya de por si una investigación. Pero no me di cuenta que este proceso no debía ser controlado por mi, aunque compañera, investigadora. Y así me lo hizo saber alguna de las compañeras del grupo cuando preparé la primera asamblea de indagación. Elaboré tres preguntas generales: ¿qué hemos hecho hasta ahora?, ¿cuál queremos que sea nuestra estrategia futura?, ¿cómo nos organizamos para llevarla a cabo?. En este encuentro, la primera confrontación que viví fue la presencia de la grabadora. Quería "recoger" las reflexiones que de allí salieran para tener algo tangible en términos metodológicos con lo que poder justificar mi presencia como investigadora. Pero, por suerte, algunas de las compañeras se negaron a ello diciendo que era un proceso de reflexión interna del grupo, que querían que fuera dinámico y no veían de la utilidad de recogerlo mediante la grabación. A esto se sumó

mediata o como una opción vital, tiene como consecuencia evidenciar la violencia estructural que sistemáticamente elitiza la vivienda y por ello forma parte de la lucha que prioriza el derecho a la vivienda por encima de la propiedad privada" (OSB, 2018). Utilizaré la palabra ocupación a lo largo de todo el texto, sin hacer ninguna distinción valorativa y con la voluntad de incluir, con esta palabra, toda aquella acción que conlleve la ocupación de un inmueble vacío para vivir.

31 Para más información visitar la web del colectivo: https://obrasocialbcn.net/ 
la dinámica improvisada que se sucedió durante las 4 horas de asamblea que tuvimos. Las preguntas que preparé fueron estratégicamente marginadas (no fue de forma consciente), lo que desestabilizó de nuevo mi presencia como investigadora. Y no fue hasta que decidí dejar de vivirme como "experta", que comencé a entender el rol de investigadora como parte de la colectividad, posicionándome en los debates auto-reflexivos como una actriz más y no tomando la voz cantante $\mathrm{u}$ organizadora.

Al final me vi atravesada e implicada en todas estas emociones sin dirección clara. La labor investigativa se volvió más un proceso de cuidados donde la reflexividad emocional (Brown y Pikerill 2009) ${ }^{32}$ me fue sirviendo para atender cómo se estaba desarrollando el grupo y hacia dónde podíamos ir. Realizamos alrededor de 6 asambleas monotemáticas en las que profundizábamos en definirnos como colectivo, tratando de consensuar cuáles serían nuestros objetivos y nuestras formas de llevarlos a cabo. Los roles en dichas asambleas iban rotando cada semana. Las tareas principales eran: dinamización de la reunión, gestión de los turnos de palabra, toma de acta de la reunión y elaboración del orden del día de la siguiente reunión. De forma simplificada el principal consenso de esas reuniones fue:

Somos un colectivo de vivienda que lucha por el derecho a la vivienda digna y el derecho a la ciudad en colaboración con otros colectivos y asambleas de barrio. Estamos en contra de la especulación con la vivienda, ya que es un derecho y no una mercancía. Trabajamos para que nadie —ni propietarios, ni empresas, ni bancos, ni instituciones - nos eche de nuestras casas, barrios y ciudades. Además, defendemos la okupación como una herramienta útil y una opción legítima para posibilitar el acceso a la vivienda digna. En Barcelona, la vivienda se está haciendo inaccesible para la mayoría de sus vecinas y su acceso queda restringido a población de renta alta, convirtiendo así un derecho en un privilegio (Acta 17/02/17)

\subsubsection{Investigación Descriminalización}

Esta investigación es aquella que iniciamos en un proceso junto a la asamblea de Obra Social Catalana (coordinación provincial de todas las comisiones de Obra Social en Cataluña). Nació como respuesta a la criminalización ejercida por el discurso mediático sobre las experiencias de la ocupación, con el objetivo de legitimar una práctica donde en muchas ocasiones, debido al contexto social, es la única opción para disponer de un techo. Así, los principales objetivos eran: desmontar los mitos/estigmas sobre las personas que ocupan y normalizar las vida de las personas que están ocupando. Para ello decidimos desde el colectivo

${ }^{32}$ Brown y Pikerill (2009) proponen la noción de reflexividad emocional como perspectiva que evidencie el rol de nuestros sentimientos en los grupos en los que militamos. Esto es, prestar la atención que se merecen a las emociones insertas en los procesos de lucha, si queremos llevar a cabo activismos sanos y sostenibles. 
OSB, por un lado, construir un material gráfico-divulgativo ${ }^{33}$, preparar acciones en los espacios públicos y realizar un informe geográfico sobre la situación ocupación en Cataluña. El informe consta ya de más de 1000 respuestas a una encuesta online y cuarenta entrevistas en profundidad a diferentes familias y personas que han estado (o están) ocupando en los últimos 2 años ${ }^{34}$. La idea de hacer un informe surgió con la pretensión de utilizar el propio lenguaje institucional y los saberes reconocidos -hablamos aquí de los saberes académicoscomo herramienta de descriminalización pública. Esto pudimos hacerlo ya que contábamos con muchas personas que provenían de la universidad o se estaban dedicando precisamente a la investigación.

Es claro que esta investigación era la más visibilizada, reconocida, sentida como útil y, por supuesto, típicamente universitaria. A pesar de utilizar la estrategia de los saberes reconocidos ${ }^{35}$ de forma consciente, dentro del grupo seguía existiendo una sacralización de esta forma de producir conocimiento en detrimento de otras y por tanto, de una división de poderes en base a los privilegios de aquellas que manejábamos las habilidades académicas. Aunque algunas personas hicieron el intento de aproximarse, pocas se quedaron y ninguna que no fuera universitaria impulsaba la misma. En este sentido se aprecia un claro corte de clase en el grupo:

Nos guste o no, somos beneficiarios del sistema ya que todavía gozamos de privilegios significativos aunque disminuidos sobre el resto de la clase obrera. Los trabajadores manuales, técnicos y de servicios consideran con razón que los trabajadores científicos pertenecen a la clase gobernante; estos últimos, como portadores de la cultura burguesa, son burgueses, por lo menos culturalmente (Gorz, 1979: 9).

Además, existía una tensión curricular en la que lo que leemos, escribimos, analizamos o producimos para esta campaña de legitimación de la ocupación, podía servirnos para nuestro tiempo de trabajo. En este sentido, aunque conservamos la autonomía de definir los tiempos, los cómos y los para qué de la investigación, existía siempre el riesgo de que las lógicas hegemónicas desesta-

33 Hasta el momento de la redacción de este artículo, habíamos hechos dos productos: una octavilla para las familias/personas que había ocupado una vivienda, donde les dábamos información básica de recursos, consejos y herramientas legales; una octavilla para aquellas familias/personas que tenían vecinos/as que habían entrado a ocupar. Animándoles a generar otro tipo de vínculos y reacciones que no pasaran por llamar a la policía.

${ }^{34} \mathrm{El}$ hecho de utilizar esta metodología cuantitativa, aunque combinada con 40 entrevistas en profundidad venía determinado por el alance de información que queríamos visibilizar. El equipo que formábamos parte de esta investigación oscilaba entre 8 y 10 personas. Y decidimos que utilizando la herramienta de la encuesta nos permitía generar una muestra más o menos representativa de las personas que habían estado ocupando durante los últimos 2 años que sirviera para no sólo visibilizar la realidad de estas personas, sino también presionar a las administraciones públicas a tomar medidas frente a esta situación. Acceso directo al informe: https://obrasocialbcn.net/ presentacio-informe-ockupacio-obra-social-bcn/informe-ockupacio/

35 Dentro del grupo había personas graduadas, doctorandas y postdoctorandas con formaciones en geografía humana, sociología y antropología social. 
bilizaran la horizontalidad y la autonomía del proceso en privilegio de carreras individuales e intereses personales curriculares y académicos.

\subsubsection{Investigación Ocupación}

Por último, la investigación en torno a la ocupación estaba principalmente destinada a sustentar y apoyar -tanto a nivel de convivencia, como judicial y estrategias de resistencia- los bloques ocupados con quienes colaboramos (vecinas organizadas, colectivos de viviendas constituidos o gente/familias individuales). Esta labor ha sido el corazón de la práctica del grupo y ha supuesto la participación de todas las personas del mismo en alguna parte del proceso. Aunque por supuesto, no todos los trabajos han tenido la misma visibilidad ni reconocimiento, la variabilidad de tareas a hacer permitió que todas nos sintiéramos útiles y pusiéramos toda nuestra energía en su realización. Desde los contactos, los comunicados, las mediaciones o las acciones de presión, invertimos nuestras habilidades en desarrollar los objetivos propuestos. Sin embargo, fue un trabajo que adquirió reconocimiento en su conjunto, obviándose todas las partes que producían conocimiento colectivamente y por tanto, los procesos de investigación que allí se estaban produciendo:

Las habilidades autodidactas o adquiridas por medio de un oficio reciben la etiqueta de «acientíficas» aun cuando, para todo propósito práctico, conlleven tanta eficacia y aprendizaje como las habilidades enseñadas institucionalmente. Y cuando buscamos una explicación de esta situación, la única que encontramos es de tipo social: el conocimiento auto-didáctico por eficaz que sea, no encaja en el patrón de la cultura dominante; y no encaja ahí porque no encaja en la división jerárquica del trabajo que es característica del capitalismo (Gorz, 1979: 5).

En este sentido, experimenté en muchas ocasiones un desprestigio de todo el trabajo de aprendizaje, indagación, resolución y colaboración que conllevan las luchas en torno a la ocupación. Siendo éstas las cuestiones más cotidianas y a la vez más combativas de la lucha y la investigación.

De forma más concreta, estos procesos de investigación se aterrizaban en varias fases y tareas concretas. Por un lado, la ocupación de un nuevo bloque supone en primer lugar la indagación acerca de la propiedad de la vivienda y el acceso a la misma, en segundo lugar la preparación del día de la entrada con todos los pasos que eso conlleva -y que no vamos a profundizar aquí- y en tercer lugar la organización de una defensa política, social y mediática del edificio. Por otro lado, cuando el bloque ya ha sido ocupado, comienza una nueva fase que implica la negociación con la propiedad, la gestión de la convivencia por parte de las vecinas que han entrado a vivir allí, además de la continuación de la defensa política, mediática y social del edificio entre otras.

Por último quiero dejar claro que estas tareas que aquí defino como investigaciones en sí mismas se realizaban mucho antes de que yo llegara al grupo. No 
he sido el motor de las mismas, pero sí parte activa junto al resto del colectivo. Las traigo aquí porque considero necesario visibilizar cómo las prácticas diarias del colectivo habían pasado desapercibidas como tareas diarias de lucha, pero no las había entendido como procesos colectivos de producción de conocimiento.

\section{CONCLUSIONES}

Me acerqué a esta investigación sabiendo su carácter experimental e inesperado, cobrando sentido a partir de experiencias concretas. Pero no me di cuenta hasta pasados unos meses de lo complejo que suponía digerir esta inestabilidad. La inseguridad de no saber cómo serían los siguientes pasos, de no actuar con ningún libro de recetas, y de pretender que ese libro lo construyera conjuntamente con un colectivo al que recién había llegado, me hacía vulnerable. Pero no sólo a mi, sino a la propia investigación.

Si ya de por sí la etnografía es un estar metodológico abierto al porvenir, las premisas de implicación-acción-colaboración (Hale, 2001) amplían aún más los horizontes. Partiendo siempre de la potencialidad de lo emergente y lo inesperado, de la "atención en el proceso" (Álvarez y Dietz, 2014: 11) y la instrumentalización de los productos, existe un claro privilegio del presente frente a proyectos pre-establecidos que otorga una gran capacidad elástica a la investigación. En este sentido la elasticidad porta un doble significado. Pues mientras por un lado, nos posibilita re-inventarnos constantemente y adaptarnos a las necesidades y realidades, por otro lado también posibilita que las acoplemos a nuestro propio interés investigativo.

Como he mencionado en las anteriores páginas, no fue hasta que reconocí que los saberes que se producían en los espacios del movimiento eran otras formas de saber igual de legítimas que las "nuestras" -las expertas, las académicas- ,que posibilité la apertura hacia una colaboración. A través de la autocrítica y la explicitación de las relaciones de poder he intentado visibilizar cómo en un comienzo privilegié el saber hegemónico universitario, impidiendo que camináramos hacia el aprendizaje de otras formas de investigar y producir conocimiento. A pesar de haber leído acerca de la necesidad de transgredir límites como acción/pensamiento, movimientos sociales/universidad, durante gran parte de mi presencia en el colectivo, no fui capaz de encontrar la manera de investigar desde la capacidad de expandir estos límites. Entre otras cuestiones porque había dibujado, como dice Leyva (2010) a la academia y al activismo como dos localizaciones rígidas y homogéneas, entre las que tienes que elegir. Por otro lado, el hecho de comenzar a formar parte de la construcción de un colectivo activó todo un proceso de subjetivación política que me convirtió en compañera de lucha, aún queriendo llevar a cabo investigaciones compartidas. Y fue este proceso de ir desde "dentro" hacia "afuera", lo que me activó una capacidad crítica que ha permitido visibilizar y poner en valor los procesos colectivos por los que estábamos pasando junto al colectivo la OSB. El formar parte del colectivo, me hizo 
situarme en una posición de horizontalidad, de igualdad de saberes y haceres, que me permitió abrir el ángulo e imaginar otras formas de colaboración.

Aún así, como "experta" en la disciplina antropológica, asumo en ciertos momentos la incapacidad de ésta para producir conocimientos que contribuyan a transformar condiciones de opresión, marginación y exclusión. Teniendo en cuenta el origen y la perpetuación del conocimiento antropológico como instrumento de dominación colonial, me atrevo a decir que continúa aportando conocimiento y técnicas de acción que, en algunas situaciones, sirven para mantener, reforzar o disfrazar estas relaciones. Desde mi experiencia, hasta que no he sido capaz de pensar e imaginar más allá de las categorías imperiales que hemos aprendido en la universidad -sobre qué es la investigación y cómo se realiza- no he podido conectar con los tiempos, necesidades y lenguajes que estaban ocurriendo en la realidad que estaba viviendo.

\section{BIBLIOGRAFÍA}

ÁLVAREZ DE ANDRÉS, E., ZAPATA, M. J., y ZAPATA, P. (2014): "Stop the evictions! The diffusion of networked social movements and the emergence of a hybrid space: The case of the Spanish Mortgage Victims Group", School of Public Administration (University of Gothenburg) Working Paper Series.

ÁLVAREZ, A. (2012): Métodos y técnicas de investigación. Apuntes tema 4. Universidad de Granada. Curso 2011-2012.

ÁLVAREZ, A., y DIETZ, G. (2014): "Etnografía colaborativa: Coordenadas desde un proyecto en curso (intersaberes)", en Simposio: Antropología y descolonialidad. Desafíos etnográfico y descolonización de las metodologías .Tarragona: Periferias, fronteras y diálogos. XII congreso de Antropología.

ÁlVAREZ, A., GARCÍA, R., FERNANDEZ, B., COTA, A. S., SEBASTIANI, L., y OLMOS, A. (2016): "Experiencias en construcción: investigación social colaborativa con el colectivo Stop Desahucios Granada 15M y la PAH de Barcelona”, en Congreso Internacional Contested Cities: del conflicto urbano a la construcción de alternativas, Madrid, Contested Cities.

ARRIBAS , A., GARCÍA-GONZÁlEZ, N., ALVAREZ, A., y ORTEGA, A. (Ed.). (2012): "Reinterpretar el mundo entero. Entrevista con Mario A.Santucho (colectivo Situaciones) Realizada por Nayra García-Gonzalez y Alberto Arribas Lozano", en Tentativas, contagios, desbordes. Territorios del pensamiento, Granada, Universidad de Granada, pp. 107-133.

ARRIBAS , A. (2014): "Lógicas emergentes de acción colectiva y prácticas colaborativas de investigación. Apuntes para una Antropología junto y con los movimientos sociales", Gazeta de Antropología, 1, 30, pp. 1-12.

BOURDIEU, P. (2002): Pensamiento y acción, Buenos Aires, Libros de Zorzal.

BROWN, G. y PICKERILL, J. (2009): "Space for emotion in the spaces of activism", Emotion, Space and Society, 2, pp. 24-35.

CAMAROFF, J. (2010): "The end of Antrhopology, again: on the future of an In/Discipline", American Anthropologist, 112 , 4, pp. 524-538.

GARCÍA, F.J., ÁLVAREZ , A. y RUBIO, M. (2011): "Prismas trasescalares en el estudio de las migraciones", Revista de Antropología Social, 20, pp. 203-228. 
CLIFFORD, J. (1995): Dilemas de la cultura. Antropología, literatura y arte en la perspectiva posmoderna, Barcelona, Gedisa.

CLIFFORD, J. (1999): Itinerarios transculturales, Barcelona, Gedisa.

CÓCOLA, G. A. (2016): "La producción de Barcelona como espacio de consumo. Gentrificación, turismo y lucha de clases", en Cartografía de la ciudad capitalista. Transformación y conflicto social en el Estado Español, Madrid, Traficantes de Sueños.

COLAU, A., y ALEMANY, A. (2012): Vidas hipotecadas. De la burbuja inmobiliaria al derecho a la vivienda, Barcelona, Cuadrilátero de libros.

COLAU, A., y ALEMANY, A. (2013): ¡Sí se puede! Crónica de una pequeña gran victoria, Barcelona, Ediciones Destino.

COTA, A. S. y SEBASTIANI, L. (2015): “Que no, que no, que no nos representan, o repensando la relación entre investigación y activismo a partir de nuestras experiencias vividas", Ankulegi, 19, pp. 43-58.

DELGADO, M. (2008): "La artistización de las políticas urbanas. El lugar de la cultura en las dinámicas de reapropiación capitalista de la ciudad", Revista electrónica de geografía y ciencias sociales, 270, 69, pp. 1-11.

DIETERICH, H. (2001): Nueva guía para la investigación científica, México, Ariel.

DOMINGO UTSET, G. (2012): "Los desahucios en la ciudad de Terrassa", Sostenible?, 13, pp. 42-52.

ESTEBAN, M. (2004): Antropología del cuerpo. Género, itinerarios corporales, identidad y cambio, Barcelona, Ediciones Bellaterra.

FERNÁNDEZ, B. I. (2016): "Tentativas comunes. Hacia una investigación comprometida junto y con la Plataforma de Afectados por la Hipoteca (PAH) de Barcelona", Trabajo Fin de Máster, Universitat de Barcelona.

FLESHER, C. (2015): "Redefining the Crisis/Redefining Democracy: Mobilising for the Right to Housing in Spain's PAH Movement”, South European Society and Politics, pp.1-21.

FREIRE, P. (1969): La educación como práctica de la libertad, Río de Janeiro, Paz e Terra.

GARCÍA, R. (2016): “Cartografias y genealogías de un tipo de activismo político: el caso de la plataforma de afectados por la hipoteca en Barcelona", Trabajo Fin de Máster, Universitat de Barcelona.

G.E.A. La Corrala (2014): "La potencialidad transformadora de la Investigación Autónoma", en Modos de trabajo artístico en contexto: itinerarios y estrategias Granada, TRN-Laboratorio artístico transfronterizo, pp. 1-8.

GORZ, A. (1979): "Sobre el carácter de clase de la ciencia y los científicos", en Economía Política de la Ciencia, México, Nueva Imagen.

GREENWOOD, D. J. (2000): "De la observación a la investigación-acción partipativa: una visión crítica de las prácticas antropológicas”, Revista de Antropología Social, 9, pp. 27-49.

GREENWOOD, D. J. (2008): “Theoretical Research, Applied Research, and Action Research. The Deinstitutionalizaion of Activist Research", en Engaging Contradictions. Theory, Politics, and Methods of Activist Scholarship, California, University of California Press, pp. 319-340.

GREGORIO, C. (2014): "Traspasando las fronteras dentro-afuera: Reflexiones desde una etnografía feminista”, Revista de Antropología Iberoamericana AIBR, 9, 3, pp. 297-322.

GUBER, R. (2001): La etnografía. Método, campo y reflexividad, Bogotá, Grupo Editorial Norma. 
HALE, C. (2001): "What is activist research?", Social Science Research Council, 2, 2, pp. 13-15.

HALE, C. (2018): "Entre el mapeo participativo y la "geopiratería: las contradicciones (a veces constructivas) de la antropología comprometida", en Prácticas otras de conocimiento(s). Entre crisis, entre guerras. Tomo I, Buenos Aires, CLACSO, pp. 299-320.

HARVEY, D. (2005): “El arte de la renta: la globalización y la mercantilización de la cultura", en Capital financiero, propiedad inmobiliaria y cultura, Barcelona, Museu d'Art Contemporani de Barcelona, pp. 29-58.

IBORRA, Y. Y CALVÓ, S. (2017): "El alquiler no puede ser una opción de vida permanentemente precaria", disponible en https://www.eldiario.es/catalunya/barcelona/ alquiler-puede-opcion-permanentemente-precaria 0 684881561.html [consulta: 16-04-2020]

LEYVA, X. (2010). “¿Academia versus Activismo? Repensarnos desde y para la práctica-teórico política” en X. Leyva et al. Conocimientos y prácticas políticas: reflexiones desde nuestras prácticas de conocimiento situado . Chiapas, México D.F., Lima y Ciudad de Guatemala, CIESAS, PDTG-USM, UNICACH, pp. s/n.

LEYVA, X. Y SPEED, S. (2018): "Hacia la investigación descolonizada: nuestra experiencia de co-labor", en Prácticas otras de conocimiento(s). Entre crisis, entre guerras. Tomo I, Buenos Aires, CLACSO, pp. 451-480.

MACÍAS, C. (2013): Del empoderamiento a la autotutela de derechos: El caso de la $P A H$. Madrid: El Viejo Topo.

MANGOT, L. (2013a): "La Plataforma de Afectados por la Hipoteca. De la Crisis a la Estafa. Del Prozac al Empoderamiento”, Clivatge, 2, pp. 56-88.

MANGOT, L. (2013b): "Cronología: burbuja, crisis y PAH”, Anuari Del Conflicte Social, pp. 272-283.

OBRA SOCIAL BARCELONA (2017): La vivienda para quien la habita. Informe sobre la ocupación de vivienda vacía en Catalunya, Barcelona, Descontrol.

OBRA SOCIAL LA PAH (2013): Manual de la Obra Social, disponible en https://afectadosporlahipoteca.com/wp-content/uploads/2013/07/MANUAL-OBRA-SOCIALWEB-ALTA.pdf [consulta: 17/04/20]

OKELY, J. (2005): “Anthropology and autobiography Participatory experience and embodied knowledge", en Anthropology y Autobiography, New York, Routledge, pp. 1-19.

OKUPA, RESISTE, CREA (2014): Reformismo y okupación. Cómo okupar y no morir en el intento, Madrid, La Rosa Negra Ediciones.

MATO, D. (2000): "Not "studying subaltern", buy studying with "subaltern" social groups, or, at least, studyng the hegemonic articulations of power", Nepantla: Views from the South, 1, 3, pp. 479-502.

MEDELA, J. R., y MONTAÑO, Ó. S. (2011): "De investigador a sujeto político: parámetros científico-metodológicos”, Espiral. Estudios sobre estado y sociedad, 18, 51, pp. 9-38.

MIR GARCIA, J., FRANÇA, J., MACÍAS, C., y VECIANA, P. (2013): “Fundamentos de la Plataforma de Afectados por la Hipoteca: activismo, asesoramiento colectivo y desobediencia civil no violenta", Educación Social, 55, pp. 52-61.

OBSERVATORIO METROPOLITANO DE BARCELONA (OMB) (2014): Comunes Urbanos en Barcelona. Prácticas de defensa, cuidado, reapropiación y gestión comunitaria, disponible en http://bcncomuns.net/wp-content/uploads/2014/06/Conclusions OMB ESP.pdf [consulta: 15-04-2020] 
PAH (2010): El Libro Verde, disponible en https://afectadosporlahipoteca.com/wpcontent/uploads/2014/01/LibroVerde-PAH-32.pdf [consulta: 16: 04: 2020]

SEBASTIANI, L., FERNÁNDEZ, B. y GARCÍA, R. (2016): "Lotte per il dritto alla casa nello Stato spagnolo: la Plataforma de Afectados por la Hipoteca. Campagnes, successi e alcune chiavi di reflessione", Interface, $2,8$.

SANTOS, B. (2010): Para Descolonizar Occidente. Más Allá del Pensamiento Abismal, Buenos Aires, CLACSO.

VECIANA, P., FRANÇA, J. y MIR GARCÍA, J. (2013): La Plataforma de Afectados por la Hipoteca y su capacidad de movilización en incidencia social, disponible en http://fes-sociologia.com/la-plataforma-de-afectados-por-la-hipoteca--y-su-capac1000ad-de-movilizacin-e-inc1000encia-social/congress-papers/1000/ [consulta: 19-17-17]

VV.AA. (2004): Nociones comunes. Experiencias y ensayos entre investigación y militancia, Madrid, Traficantes de Sueños.

VILLASANTE, T. R. (2010): Historias y enfoques de una articulación metodológica participativa, Cuadernos 